\title{
In ineffective esophageal motility, failed swallows are more functionally relevant than weak swallows
}

\author{
\begin{tabular}{l|l|l} 
A. Jain (i) | J. R. Baker | J. W. Chen &
\end{tabular}
}

Division of Gastroenterology, University of Michigan Health System, Ann Arbor, MI, USA

\section{Correspondence}

Joan W Chen, MD, MS, Division of Gastroenterology, University of Michigan Health System, Ann Arbor, MI, USA

Email: chenjoan@med.umich.edu

\begin{abstract}
Background: Esophageal pressure topography (EPT) diagnosis of ineffective esophageal motility (IEM) can be non-specific with unclear clinical significance.

Aims: To determine whether peristaltic vigor or lower esophageal sphincter (LES) integrity is associated with poor clearance and acid reflux in IEM.

Methods: Bolus clearance on high-resolution impedance manometry (HRIM) and available reflux studies in patients with IEM were retrospectively reviewed. Bolus clearance was assessed using both line tracing and colored contour methods on HRIM. EPT parameters, bolus clearance, and acid reflux variables were explored.

Key Results: Eighty-eight patients with IEM were included. Bolus clearance occurred in $71 \%$ of all swallows, and $55.7 \%$ of patients had complete bolus transit (CBT, bolus clearance in $\geq 80 \%$ of swallows). Bolus clearance was impaired in swallows with distal contractile integral $(\mathrm{DCl})<100 \mathrm{mmHg} \bullet \mathrm{cm} \bullet \mathrm{s}$ compared to $\mathrm{DCl} 100-450$ ( 0.43 vs 0.79 , $P<.0001)$. A cutoff at $\mathrm{DCl} 100 \mathrm{mmHg} \bullet \mathrm{cm} \bullet \mathrm{s}$ was associated with clearance with an accuracy of $76 \%$ compared to $49 \%$ at $\mathrm{DCl} 450$ ( $P=.0001$ for both). A median $\mathrm{DCl}$ $<100$ was associated with a higher Eckardt score ( 9 vs 3, $P=.03$ ), and on reflux testing available in 47 patients, with abnormal acid exposure time $(P=.002)$. Peristaltic reserve (PR) defined as ( $\mathrm{DCl}$ of multiple rapid swallow/median $\mathrm{DCl}$ of wet swallows), integrated relaxation pressure, and resting lower esophageal sphincter pressure were not associated with clearance or acid exposure.

Conclusions \& Inferences: Failed peristalsis, as defined by $\mathrm{DCl}<100 \mathrm{mmHg} \bullet \mathrm{cm} \bullet$ s, is associated with impaired bolus clearance and more severe dysphagia in IEM, and likely abnormal acid exposure.
\end{abstract}

KEYWORDS

esophagus, GERD, impedance, manometry, motility

\section{1 | INTRODUCTION}

Ineffective esophageal motility (IEM), a non-specific or minor motility disorder characterized by a combination of weak and failed peristalsis,

Abbreviations: AET, acid exposure Time; AUC, area-under-the-curve; BFT, bolus flow time; $\mathrm{CBT}$, complete bolus transit; $\mathrm{DCl}$, distal contractile integral; EGJOO, esophagogastric junction outflow obstruction; Ell, esophageal impedance integral; EPT, esophageal pressure topography; FC, functional clearance; HRM, high-resolution manometry; HRIM, high-resolution impedance manometry; IRB, Institutional Review Board; IRP, integrated relaxation pressure; LES, lower esophageal sphincter; PFA, pressure-flow-analysis; PPI, proton-pump inhibitor; $\mathrm{PR}$, peristaltic reserve; $\mathrm{ROC}$, receiver operating characteristic. is a frequent esophageal manometric finding oftentimes with unclear clinical significance. With the implication of poor esophageal emptying, IEM has been associated with prolonged acid exposure and peptic complications, ${ }^{1,2}$ as well as symptomatic non-obstructive dysphagia. ${ }^{3}$ The definition of IEM has evolved over time. In the conventional line tracing (CLT) era, IEM was defined as low-amplitude $(<30 \mathrm{~mm} \mathrm{Hg}$ ) distal esophageal contractions in $50 \%$ or more wet swallows. Using this definition, studies have found impaired liquid bolus transit in up to $70 \%$ of patients with IEM, ${ }^{4-6}$ and the association of IEM with gastro-esophageal reflux disease (GERD) had been assessed. ${ }^{7,8}$ Since 
the introduction of high-resolution manometry (HRM), the CLT definition of IEM was initially translated in esophageal pressure topography (EPT) as weak peristalsis with small and large peristaltic defects or frequently $(>30 \%)$ failed peristalsis, then more recently as $50 \%$ or more swallows with a distal contractile integral (DCI) less than $450 \mathrm{mmHg} \bullet \mathrm{cm} \bullet \mathrm{s}^{9}{ }^{9}$ An evaluation of bolus transit in the current EPT diagnosis of IEM has not been conducted. Furthermore, correlation of impaired bolus transit in IEM with symptoms and distal esophageal acid exposure has not been evaluated.

IEM is the most common manometric abnormality (up to $20-30 \%)^{5}$; yet, a standard clinical approach for this diagnosis does not exist. Moreover, the clinical relevance and benefit of treating IEM is unclear for several reasons. Many patients with this manometric finding are asymptomatic, and those symptomatic have variable complaints including dysphagia, cough, or reflux symptoms. ${ }^{10}$ Management of IEM is challenging as the impact of weakened peristaltic vigor on symptoms is uncertain, and prior studies have associated minor esophageal motor abnormalities with good long-term prognosis even with minimal intervention. ${ }^{11}$ There is currently no therapeutic intervention that reliably restores smooth muscle contractility in patients with IEM. Use of bethanechol, a muscarinic receptor agonist shown to be effective in improving esophageal contraction in small case series of IEM patients, has been limited by side effects of dizziness, headaches, nausea, and vomiting, that frequently outweigh potential clinical benefits. ${ }^{12,13}$ In IEM patients with refractory reflux, tailored fundoplication is sometimes employed as the management strategy; however, this approach has not been shown to be beneficial. ${ }^{14}$

The most recent iteration of the Chicago Classification v3.0 has retained its definition of IEM as a minor motility disorder, ${ }^{15}$ where the clinical significance of the condition continues to be actively debated. There has been significant interest in phenotyping IEM based on the degree of peristaltic impairment and using multiple rapid swallows (MRS) to characterize peristaltic reserve (PR), the $\mathrm{DCl}$ ratio after MRS/median DCl of the 10 swallows. ${ }^{16-19}$ The aim of our study was to determine whether the degree of impairment in peristaltic vigor, as measured by $\mathrm{DCl}$ and $\mathrm{PR}$, or lower esophageal sphincter integrity is associated with poor clearance and acid reflux in IEM. We set out to determine the parameter and its threshold value that would help identify the subpopulation of IEM patients with poor bolus transit.

\section{2 | MATERIALS AND METHODS}

\section{1 | Study design}

This was a cross-sectional retrospective cohort study. Consecutive high-resolution impedance manometry (HRIM) procedures performed in adult patients (older than 18 years of age) in the Gastrointestinal Physiology Lab at the University of Michigan between February of 2015 and May of 2016 were screened for the diagnosis of weak peristalsis, frequently failed peristalsis, and IEM. HRIM tracings for included patients were reviewed again to confirm an accurate diagnosis of IEM per Chicago Classification v3.0. Study protocol was approved by the Institutional Review Board (IRB) at the University of Michigan.

\section{Key Points}

- Ineffective esophageal motility (IEM) is an esophageal motility disorder with unclear clinical implications. We aim to determine whether strength of peristalsis, peristaltic reserve, or lower esophageal sphincter integrity predicts symptoms or clinical outcomes.

- We found that a distal contractile integral (DCl) of $<100 \mathrm{mmHg} \bullet \mathrm{cm} \bullet \mathrm{s}$ is associated with impaired bolus clearance and a higher degree of dysphagia in IEM.

- Treatment of IEM should be conservative when $\mathrm{DCl}$ is $>100 \mathrm{mmHg} \bullet \mathrm{cm} \bullet \mathrm{s}$. More aggressive treatment of present reflux disease and prokinetic agents may be indicated when $\mathrm{DCl}$ is $<100$.

\subsection{Review of medical record}

The electronic medical records of included subjects were reviewed. Data obtained included demographic information, medical and surgical history, medications, diagnostic testing such as endoscopy, barium esophagram, $\mathrm{pH}$ testing, esophageal symptoms, and patient reported outcome (PRO) questionnaires which included Eckardt, brief esophageal dysphagia questionnaire (BEDQ), and GERDQ. ${ }^{20-22}$

\section{3 | Manometry and intraluminal impedance measurement}

Patients underwent manometry using a combined high-resolution manometry and intraluminal impedance (HRIM) system. This is a solid-state assembly with 36 levels of pressure sensors and 12 impedance-sensing segments (Medtronic, Dublin, Ireland). The response characteristics of this device, calibration procedure, and poststudy thermal correction algorithm have been described in detail previously. ${ }^{23}$ Briefly, the HRIM assembly was passed transnasally and positioned to record from the hypopharynx to the stomach with about 5 intragastric sensors. The manometric protocol included a 5-minute period for acclimatization and to assess basal sphincter pressure followed by ten $5 \mathrm{ml}$ liquid swallows of $0.45 \%$ saline in the supine position. In most studies, an additional MRS sequence involving five $2 \mathrm{ml}$ swallows every 2-3 seconds was performed in the upright position. The combined pressure-impedance data were manually analyzed using the ManoView ESO v.3.0.1 software (Medtronic). After thermal compensation, the HRM studies were manually analyzed in accordance with the Chicago Classification v3.0. After confirming the diagnosis of IEM, data for individual swallows were extracted by documenting the values for each parameter: basal lower esophageal sphincter (LES) pressure, distance between LES-crural diaphragm (LES-CD), integrated relaxation pressure (IRP), and $\mathrm{DCl}$. DCl after multiple rapid swallows (MRS) was also recorded. 
Then, the color isobaric contour plots were overlaid with impedance line tracings by selecting the "enabling impedance trace on contour" option. The display mode button was changed to impedance tracing on contour (colored contour and lines). Included studies were re-analyzed retrospectively by a single primary reader blinded to the clinical profile. Bolus transit was assessed via line tracing and contour methods as below. A second reader blindly reviewed 22 (25\%) randomly selected studies for comparison.

\section{4 | Bolus clearance}

\subsection{1 | Complete bolus transit}

Bolus transit was assessed for each swallow using impedance line tracings. Bolus entry was defined as a $>50 \%$ drop in impedance level from baseline at the proximal recording site, and complete bolus transit (CBT) was defined as a $>50 \%$ drop from baseline followed by an increase back to at least $50 \%$ from impedance nadir at the three distal recording sites following bolus entry. ${ }^{3}$ In instances where the impedance baseline before each swallow was low indicating retained bolus pre-swallow, impedance baseline during the "landmark-ID" measurement period was used as the reference impedance level to assess bolus transit. Each of the 10 wet swallows was scored as either complete or incomplete bolus clearance. Examples of complete and incomplete bolus transit are shown in Figure 1.

\subsection{2 | Functional clearance}

Bolus clearance was also assessed via a colored contour method. Impedance data were displayed as a monochrome color gradient overlaying the pressure topography by changing the contour mode. The color contrast, manually adjustable by changing the level of impedance indication in kiloohm, was adjusted so that the contour showed an emptying esophagus before initiation of the $0.45 \%$ saline swallow sequence, and the liquid ingested with each swallow was just visible. Bolus clearance was defined by the absence of bolus in the distal esophagus after each swallow. Incomplete functional clearance (FC) was defined as evidence of residual fluid bolus in the distal esophagus.

\section{5 | 24-Hour multichannel intraluminal impedance- $\mathrm{pH}(\mathrm{MII}-\mathrm{pH})$ monitoring}

The combined $\mathrm{pH}$-impedance assembly (Sandhill Scientific, Highlands Ranch, CO, USA) was positioned with the proximal pH electrode $5 \mathrm{~cm}$ above the manometrically identified lower esophageal sphincter (LES). Impedance was measured 3, 5, 7, 9, 15, and $17 \mathrm{~cm}$ above the LES. Event markers recorded occurrence of symptoms, meals, and changes in posture. The recorded data were analyzed in accordance with previously published criteria. ${ }^{24}$ Total percent time $\mathrm{pH}<4$, or the acid exposure time (AET), was chosen as the primary reflux parameter. Active proton-pump inhibitor (PPI) usage and dosing was noted. An AET of
(A)

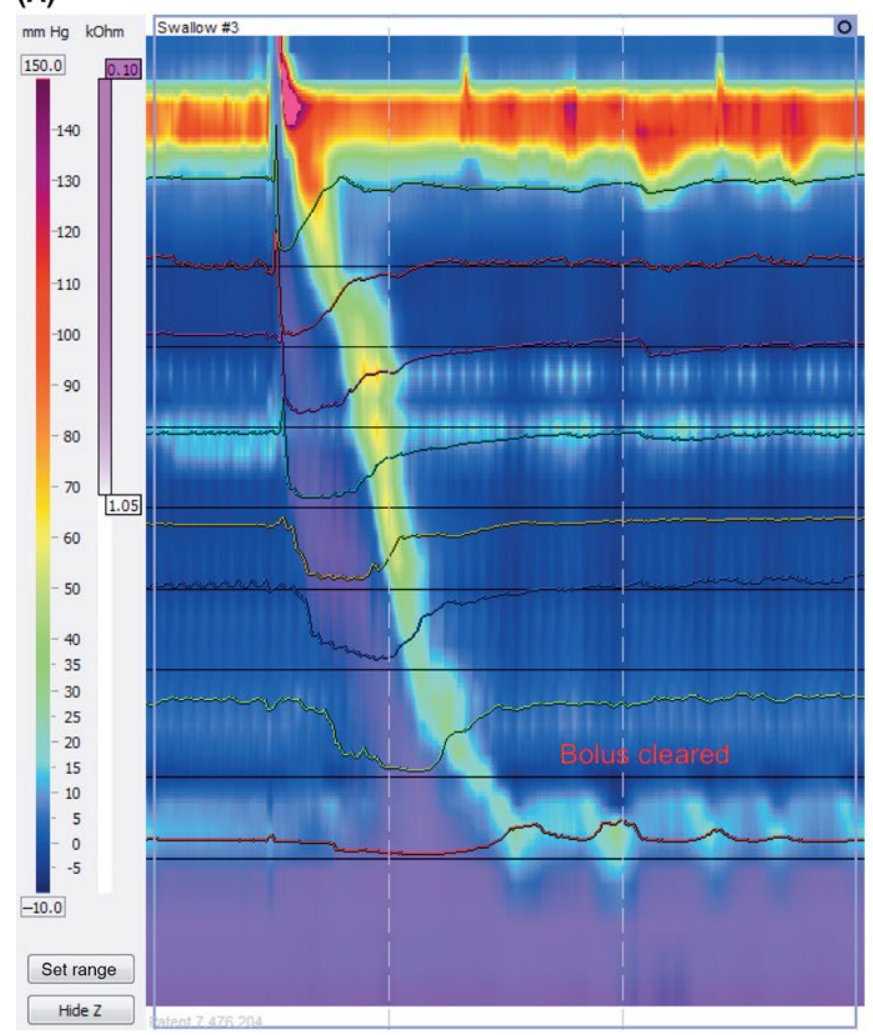

(B)

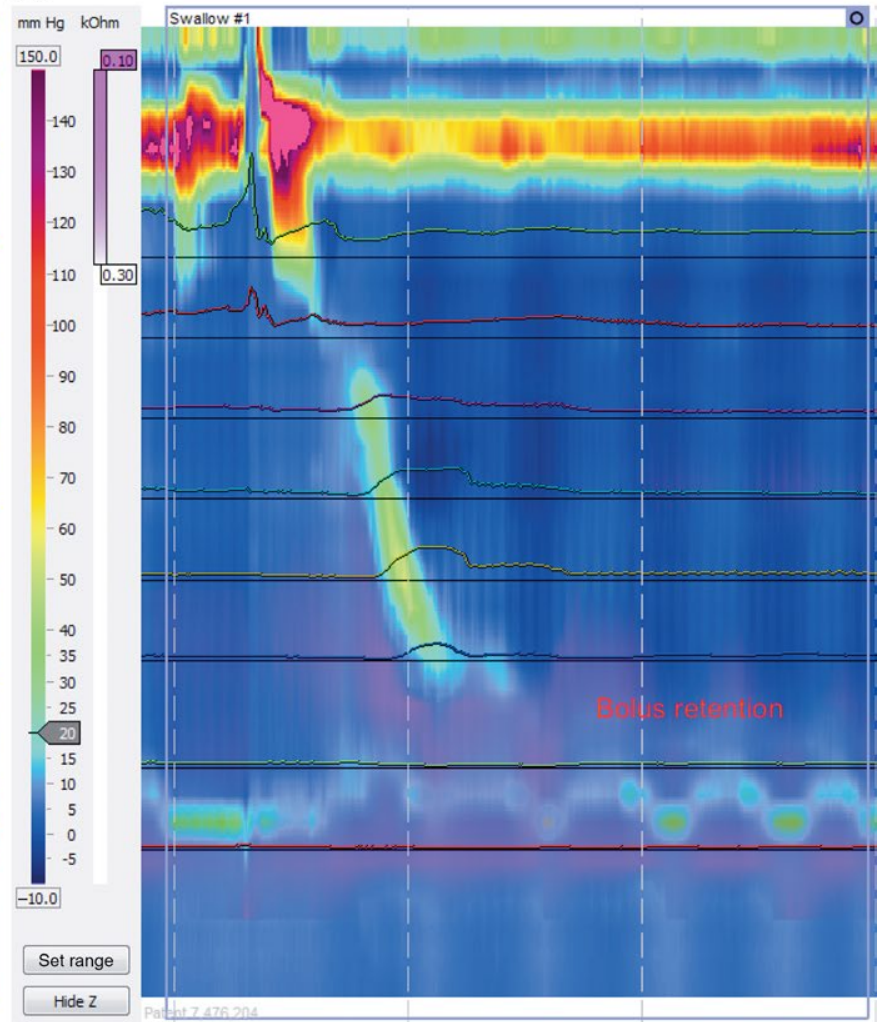

FIGURE 1 High-resolution impedance manometry (HRIM) depictions of bolus clearance in ineffective esophageal motility. Conventional impedance line tracings are superimposed on HRIM plots with colored impedance contour. Panel A shows an example of complete bolus transit; Panel B shows an example of incomplete clearance 
$>4.2 \%$ off PPI, and an AET of $>1.6 \%$ on PPI were considered abnormal. ${ }^{25}$ All MII-pH studies were performed on the same day as HRIM or within 4 months afterwards.

\subsection{Statistical methods}

CBT and FC were determined for each of 10 supine swallows. Agreement between $\mathrm{CBT}$ and $\mathrm{FC}$ was calculated across all supine swallows. CBT frequency was calculated in swallows in distinct $\mathrm{DCl}$ subgroups. Receiver-operating characteristic (ROC) curve was constructed for CBT based on DCl for all swallows. ROC curves for complete bolus transit defined as CBT in $80 \%$ or more of 10 supine swallows were constructed based on \% ineffective swallows and \% failed swallows. ${ }^{5}$ Cutoff values for ROC curves were selected using the Youden's index. Logistic regression analysis was performed to evaluate associations between $C B T$ and $A E T$ with the following variables as relevant: IRP, resting LES pressure, $\mathrm{PR}$, median $\mathrm{DCl}$, mean $\mathrm{DCl}$. Correlation between elevated $\mathrm{AET}$ and $\mathrm{DCl}$ at our chosen cutoff was assessed. Parametric variables were compared using unpaired $t$ test. Non-parametric variables were compared using the MannWhitney test. Categorical variables were analyzed using a chi-squared or Fisher's exact test. A $P$ value of .05 was considered statistically significant for all analyses. On ROC curves, an area-under-the-curve (AUC) greater than 0.70 was deemed sufficient for categorical analysis.

\section{3 | RESULTS}

\section{1 | Sample description}

Eighty-eight adult patients with a confirmed EPT diagnosis of IEM were included in this analysis. Eighty-seven of these studies were originally diagnosed using Chicago Classification V3.0 criteria; one study was reclassified from frequent failed peristalsis on V2.0 to IEM. Seventy-five patients had available multiple rapid swallows. Ten patients with IEM had a history of prior fundoplication. Forty-seven patients had available MII-pH testing after excluding patients with prior fundoplication. Sixteen of these studies were performed on patients off PPI therapy and the remaining 31 studies were performed in patients on PPI therapy.

Demographics and relevant clinical data are displayed in Table 1. The mean age in our IEM group was 53.1 (SD 16.5); female: male ratio was 1.6. In addition to the 10 patients with prior fundoplication, 1 patient each with prior Roux-en-Y gastric bypass (RNYGB) and sleeve gastrectomy were included. One patient with eosinophilic esophagitis and 3 patients with scleroderma were included. The indications for manometry were dysphagia (44\%), GERD (37\%), nausea (6\%), cough (3\%), pre-lung transplant evaluation (3\%), chest pain (2\%), dyspnea (2\%), globus (1\%), and abdominal pain (1\%). HRIM characteristics based on age and body mass index (BMI) are shown in Table 2. A breakdown of all symptoms in the IEM group is shown in Table 3. Reflux-like symptoms including heartburn and/or regurgitation were the most prevalent symptoms in $60.2 \%$ of patients, followed by dysphagia in $45.5 \%$, abdominal pain in $26.1 \%$, and nausea in $23.9 \%$. Seventy-nine percent of patients with heartburn and/or regurgitation were on a PPI; $82.5 \%$
TABLE 1 Clinical data $(\mathrm{N}=88)$

\begin{tabular}{lc} 
Age (mean) [range] & $53.1[20-83]$ \\
Sex (\%) & \\
Male & $34(39 \%)$ \\
Female & $54(61 \%)$ \\
Body mass index (mean) [SD] & $28.1[5.4]$ \\
Other UGI history (\%) & \\
Fundoplication & $10(11.3 \%)$ \\
RNYGB & $1(1.1 \%)$ \\
Sleeve gastrectomy & $1(1.1 \%)$ \\
Eosinophilic esophagitis & $1(1.1 \%)$ \\
Scleroderma & $3(3.4 \%)$ \\
\hline
\end{tabular}

SD, standard deviation; RNYGB, Roux-en-Y gastric bypass; UGI, upper gastrointestinal.

TABLE 2 HRIM characteristics by age and BMI

\begin{tabular}{|cccccc|}
\hline & Number & IRP & Basal LES-P & DCI & $\%$ CBT \\
\hline Age & & & & & \\
\hline$<40$ & 19 & 4.7 & 12.7 & 271.5 & $63.1 \%$ \\
\hline $41-60$ & 31 & 6.2 & 17 & 279 & $45.1 \%$ \\
\hline$>60$ & 38 & 6.4 & 19 & 257 & $60.5 \%$ \\
\hline BMI & & & & & \\
\hline$<25$ & 26 & 5.9 & 23.7 & 276 & $61.5 \%$ \\
\hline $25-30$ & 32 & 4.8 & 15.3 & 255 & $46.8 \%$ \\
\hline$>30$ & 23 & 7.1 & 16 & 192 & $60.8 \%$ \\
\hline
\end{tabular}

$\mathrm{BMI}$, body mass index; $\mathrm{CBT}$, complete bolus transit; $\mathrm{DCl}$, distal contractile integral; HRIM, High-resolution impedance manometry; IRP, integrated relaxation pressure; LES-P, lower esophageal sphincter pressure.

of patients with dysphagia were on a PPI. Prevalence of certain medication classes prescribed to IEM patients are also shown in Table 3. Opioids were prescribed in $20.4 \%$ of patients. Esophageal testing data is shown in Table 4. Dysmotility on esophagram was seen in $61.4 \%$, gastro-esophageal reflux in $52.6 \%$. Erosive esophagitis or Barrett's was noted in $26.2 \%$ of upper endoscopies. Hiatal hernia was noted on manometry in $29.5 \%$.

\section{2 | Bolus transit}

Proportion of CBT and FC in 880 swallows in IEM patients were 0.71 and 0.73 , respectively, with a kappa value of 0.83 , indicating excellent agreement between the two methods to assess bolus transit on HRIM. The ROC curve for CBT according to $\mathrm{DCl}$ is shown in Figure 2. The AUC was 0.77 . A DCl of less than $100 \mathrm{mmHg} \bullet \mathrm{cm} \bullet \mathrm{s}$ had the best accuracy (76\%) for impaired bolus transit, and a negative predictive value of $83 \%$ $(P=.0001)$. A DCl of cutoff of $450 \mathrm{mmHg} \bullet \mathrm{cm} \bullet \mathrm{s} \mathrm{had}$ an accuracy of $49 \%$ $(P=.0001)$. CBT and $\mathrm{FC}$ in $\mathrm{DCl}$ subgroups are shown in Figure 3. The largest step-off was noted between the $\mathrm{DCl}<100$ (CBT 0.43, FC 0.42) and $\mathrm{DCl} 100-249$ groups (CBT 0.77, FC 0.78). In the $\mathrm{DCl}>450$ group, CBT was 0.91 and FC was 0.92 . When CBT in each group was compared 
to the other 3 groups using Mann-Whitney test, all were statistically significant other than the DCl 100-249 group ( $P$ values .0001-.10 as shown in Figure 3 ). Agreement with a second reader in $25 \%$ of randomly selected studies was excellent ( $k=0.80$ for $\mathrm{CBT}, k=0.83$ for $\mathrm{FC}$ ).

TABLE 3 Symptoms and medication use $(\mathrm{N}=88)$

\begin{tabular}{|l|l|}
\hline Symptom & $\%$ of patients \\
\hline Heartburn and/or regurgitation & $60.2 \%$ \\
\hline Dysphagia & $45.5 \%$ \\
\hline Abdominal pain & $26.1 \%$ \\
\hline Nausea & $23.9 \%$ \\
\hline Cough & $17.0 \%$ \\
\hline Class of medication & \\
\hline Opioids & $20.4 \%$ \\
\hline Calcium channel blockers & $8.0 \%$ \\
\hline Muscle relaxants & $6.8 \%$ \\
\hline Tricyclic antidepressants & $6.8 \%$ \\
\hline Nitrates & $3.4 \%$ \\
\hline
\end{tabular}

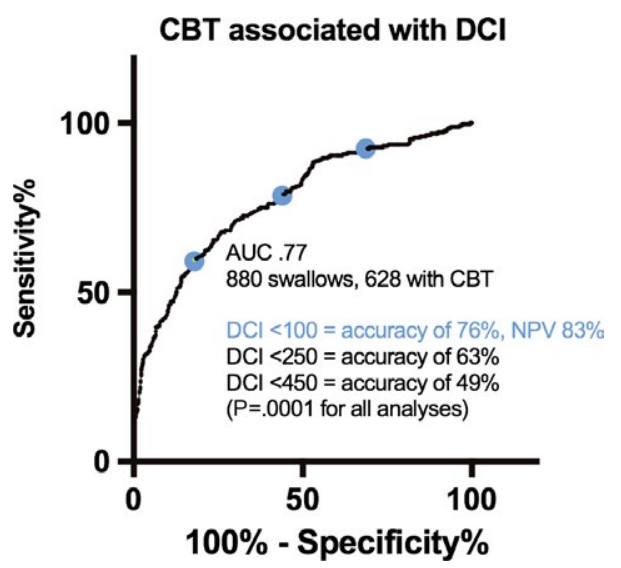

FIGURE 2 Receiver operating characteristic curve of complete bolus transit (CBT) in association with distal contractile integral (DCI) in all supine swallows. AUC, area-under-the-curve; NPV, negative predictive value
Complete bolus transit in $\geq 80 \%$ of swallows was observed in $55.7 \%$ of patients. ROC curves for all ineffective swallows (weak and failed) and failed swallows alone in association with complete bolus transit in $80 \%$ or more swallows are in shown in Figure 4 . The AUC for all ineffective swallows was 0.52, whereas for failed swallows only it was 0.73 . Failed swallows $\geq 30 \%$ had an accuracy of $72 \%$ and a NPV of $80 \%(P=.0001)$. On logistic regression analysis, mean $\mathrm{DCl}$ and median $\mathrm{DCl}$ were associated with complete bolus transit $(P$ values .04 and .05 , respectively); however, in individual ROC curve analysis, AUCs were low at 0.57 and 0.60 respectively. $\mathrm{DCl}$ after multiple rapid swallow (MRS) and the peristaltic reserve (PR = DCI MRS/ wet swallows ratio) were not associated with complete bolus transit.

We performed a secondary analysis of CBT in association with $\mathrm{DCl}$ across all supine swallows, excluding patients with any foregut surgery history $(\mathrm{N}=76$ ). The AUC was similar at 0.76 , and a $\mathrm{DCl}$ of $<100 \mathrm{mmHg} \bullet \mathrm{cm} \bullet \mathrm{s}$ was associated with impaired clearance $(P=.0001)$ with accuracy of $77 \%$ and NPV $84 \%$.

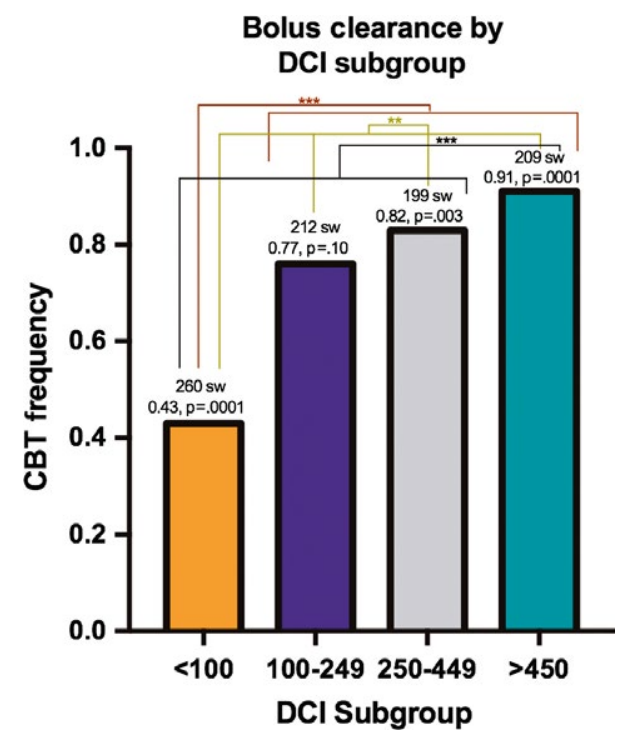

FIGURE 3 Complete bolus transit compared among different distal contractile integral ( $\mathrm{DCl}$ ) groups in ineffective esophageal motility. Lines indicate comparisons to other groups. Asterisks (*) indicate presence of and magnitude of statistical significance
FIGURE 4 Receiver operating characteristic curves showing incomplete clearance in association with ineffective swallows (Panel A) and failed swallows only (Panel B). AUC, area-under-the-curve; NPV, negative predictive value
(A) $\%$ Ineffective swallows and incomplete clearance (CBT < 80\%)

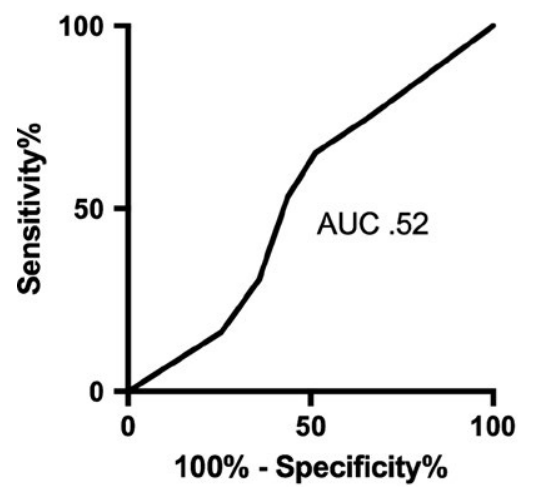

(B) \% Failed swallows and incomplete clearance (CBT < 80\%)

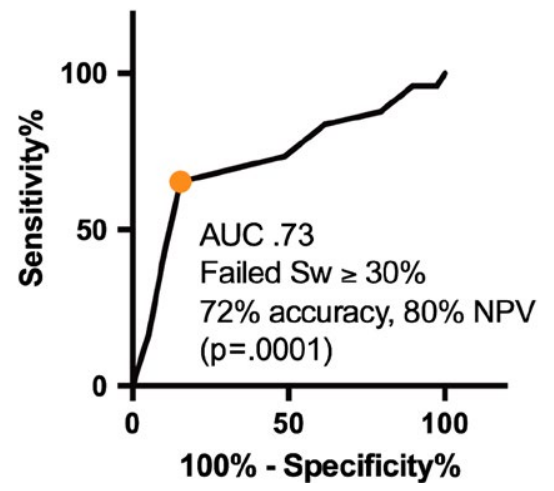




\section{Eckardt}
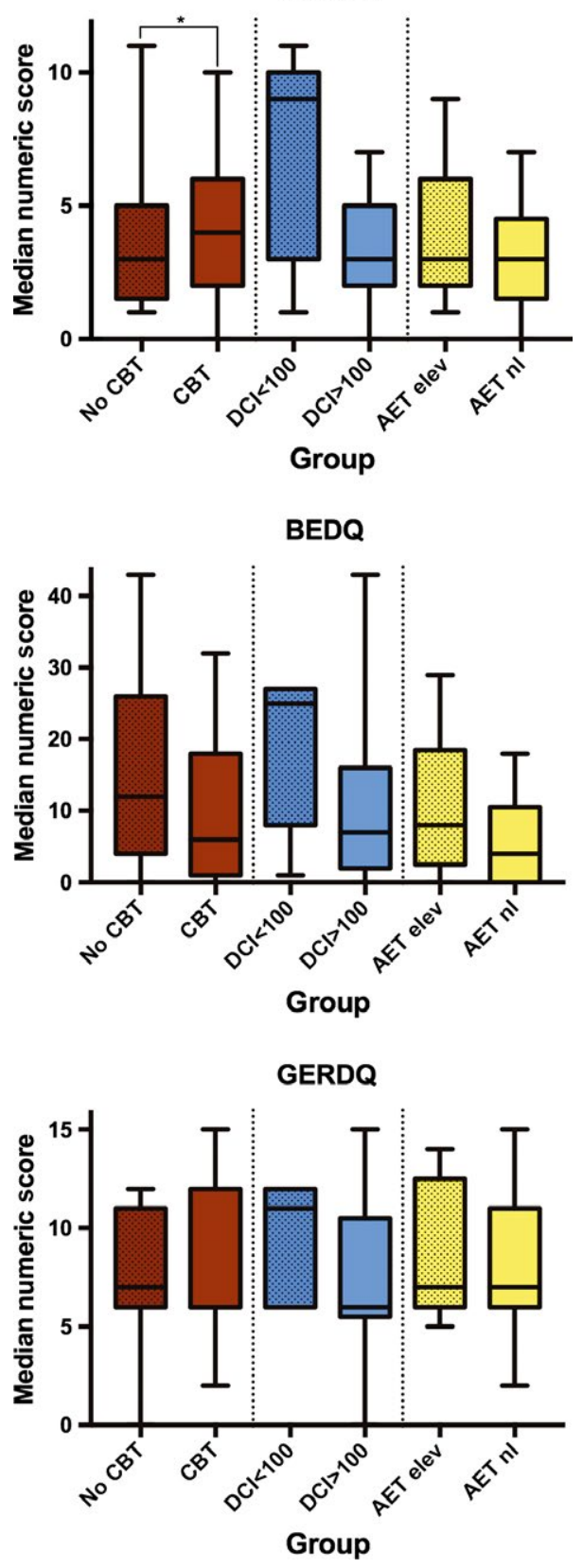

FIGURE 5 Box-and-whisker plots showing median scores for Eckardt, BEDQ, brief esophageal dysphagia questionnaire, and GERDQ, gastro-esophageal reflux disease questionnaire based on clearance; $\mathrm{AET}$, acid exposure time; and $\mathrm{DCl}$, median distal contractile integral per patient. Asterisk (*) indicates statistical significance. CBT, complete bolus transit

\section{3 | Acid exposure time}

With exclusion of patients with prior fundoplasty, 23 of 47 patients $(48.9 \%)$ had an elevated AET. No associations between mean $\mathrm{DCl}$, median $\mathrm{DCl}$, resting LES, median IRP, MRS DCI, or PR and elevated AET were found. However, on categorical analysis, all 8 patients with a median $\mathrm{DCl}<100 \mathrm{mmHg} \bullet \mathrm{cm} \bullet \mathrm{s}$ had an elevated AET (PPV 100\%, accuracy 68.1\%, $P=.002$ ). When median
TABLE 4 Esophageal diagnostic testing

\begin{tabular}{|c|c|}
\hline \multicolumn{2}{|l|}{ Esophagram ( $N=57)$} \\
\hline Dysmotility & $35(61.4 \%)$ \\
\hline Reflux & $30(52.6 \%)$ \\
\hline Hiatal hernia & $24(42.1 \%)$ \\
\hline Normal & $5(8.8 \%)$ \\
\hline \multicolumn{2}{|l|}{ Upper endoscopy ( $N=72)$} \\
\hline Erosive esophagitis & $11(15.2 \%)$ \\
\hline Barrett's & 8 (11.0\%) \\
\hline \multicolumn{2}{|l|}{$\mathrm{pH}$ testing $(\mathrm{N}=47)$} \\
\hline Off PPI therapy (\%) & $16(34 \%)$ \\
\hline Elevated AET (\%) & 5 (31.3\%) \\
\hline On PPI therapy (\%) & $31(66 \%)$ \\
\hline Elevated AET (\%) & $18(58.1 \%)$ \\
\hline Elevated AET overall (\%) & $23(48.9 \%)$ \\
\hline \multicolumn{2}{|l|}{ HRIM (N = 88) } \\
\hline Complete bolus transit & 49 (55.7\%) \\
\hline LES-CD $\geq 2 \mathrm{~cm}$ & $26(29.5 \%)$ \\
\hline \multicolumn{2}{|l|}{$\mathrm{DCl}(\mathrm{mmHg} \bullet \mathrm{cm} \bullet \mathrm{s})$} \\
\hline Mean [SD] & 341 [218] \\
\hline Median [range] & 218 [21-1035] \\
\hline \multicolumn{2}{|l|}{ IRP (mm Hg) } \\
\hline Mean [SD] & $6.0[3.8]$ \\
\hline Median [range] & $5.9[0.9-13.1]$ \\
\hline \multicolumn{2}{|l|}{ Basal LES pressure (mm Hg) } \\
\hline Mean [SD] & $19.7[11.6]$ \\
\hline Median [range] & $17.5[4.8-41]$ \\
\hline
\end{tabular}

AET, acid exposure time; $C D$, crural diaphragm; $D C l$, distal contractile integral; HRIM, High-resolution impedance manometry; IRP, integrated relaxation pressure; LES, lower esophageal sphincter; PPI, proton-pump inhibitor; SD, standard deviation.

$\mathrm{DCl}$ was $>100 \mathrm{mmHg} \bullet \mathrm{cm} \bullet \mathrm{s}, 25 / 40$ (61.2\%) of patients had a normal AET.

Separating acid exposure by PPI use- 5 of 16 patients (31.3\%) off PPI and 18 of 31 (58.1\%) on PPI had an elevated AET. There were no differences in median $\mathrm{DCl}, \mathrm{CBT}$, or MRS augmentation ratio in association with elevated AET using this grouping. However, there appeared to be a trend toward impaired MRS augmentation in the elevated AET group off PPI (ratio of 0.1 vs 2.2).

We performed a separate analysis of the 46 patients without any foregut surgery, excluding an additional patient with a prior sleeve gastrectomy. Median $\mathrm{DCl}<100 \mathrm{mmHg} \bullet \mathrm{cm} \bullet \mathrm{s}$ remained associated with an elevated AET in all 8 patients, and 25/39 (64.1\%) of patients with a median $\mathrm{DCl}>100 \mathrm{mmHg} \bullet \mathrm{cm} \bullet \mathrm{s}$ had a normal AET.

\section{4 | Patient reported outcomes (PRO)}

PRO questionnaires were collected from a total of 38 patients with IEM at the time of HRIM. These included 38 Eckardt, 36 BEDQ, and 36 completed GERDQ surveys. In patients with available MII-pH 
TABLE 5 Patient reported outcomes

\begin{tabular}{|c|c|c|c|c|c|c|}
\hline & \multicolumn{2}{|l|}{ Eckardt } & \multicolumn{2}{|l|}{ BEDQ } & \multicolumn{2}{|l|}{ GERDQ } \\
\hline CBT & $4[2-6]$ & .36 & $6[2.5-15]$ & .15 & $6[6-11.5]$ & .98 \\
\hline No CBT & $3[2-5]$ & & $12[5-25]$ & & $7[6-11]$ & \\
\hline AET nl & $3[2-4]$ & .99 & $4[0-10]$ & .19 & $7[6-10]$ & .80 \\
\hline AET elev & $3[2-5]$ & & 8 [4-12] & & 7 6-12] & \\
\hline $\mathrm{DCl}<100$ & 9 [3.5-9.5] & & $25[10-26]$ & & $11[6.5-12]$ & \\
\hline AET nl (off PPI) & $4[2-5]$ & .20 & $4[0-14]$ & $>.99$ & 7 [6-13] & .33 \\
\hline AET elev (off PPI) & $1.5[1-2]$ & & $3.5[0-7]$ & & $5.5[5-6]$ & \\
\hline AET nl (on PPI) & $3[1-5]$ & .38 & 5 [0-10] & .11 & $6.5[6-10]$ & .27 \\
\hline
\end{tabular}

AET, acid exposure time; BEDQ, brief esophageal dysphagia questionnaire; CBT, complete bolus transit; DCl, distal contractile integral; GERDQ, gastroesophageal reflux disease questionnaire; IQR, interquartile range.

testing, 24 Eckardt scores, 22 BEDQ scores, and 22 GERDQ surveys were collected. Median scores for patients with complete and incomplete bolus transit, normal and elevated AET, and DCI >100 and $<100 \mathrm{mmHg} \bullet \mathrm{cm} \bullet \mathrm{s}$ are shown in Figure 5 and Table 5. There was a trend toward higher scores when median $\mathrm{DCl}$ was $<100$, with a statistically significant difference in Eckardt score (9 vs 3, $P=.03$ ). Although no statistically significant differences were noted with abnormal CBT or AET, a trend toward higher BEDQ scores was noted with abnormal CBT and elevated AET.

\section{4 | DISCUSSION}

The latest iteration of the Chicago Classification reinstated the diagnosis of ineffective esophageal motility, which is now defined as decreased contractile vigor with $\mathrm{DCl}<450 \mathrm{mmHg} \bullet \mathrm{cm} \bullet$ s in $50 \%$ or more swallows. This includes a combination of weak and failed swallows. However, the clinical significance of IEM remains unclear. Attempts at subtyping IEM based on type of abnormal bolus transit (viscous, liquid, or both), and most recently, degree of peristaltic dysfunction ${ }^{17}$ have been made. Since transition to EPT, no studies have attempted to phenotype IEM using impaired bolus transit on intraluminal impedance as the primary indicator of clinically significant IEM.

Our study showed that a $\mathrm{DCl}$ of less than $100 \mathrm{mmHg} \bullet \mathrm{cm} \bullet \mathrm{s}-$ the $\mathrm{DCl}$ threshold used for failed peristalsis-identifies a phenotypically more severe subgroup of IEM with decreased bolus clearance, more severe dysphagia, and likely abnormal acid exposure. Our results support $\mathrm{DCl}$ as the most functionally relevant metric in evaluation of IEM, over the IRP or the peristaltic reserve. The most clinically relevant finding is that patients with a median $\mathrm{DCl}$ of $>100 \mathrm{mmHg} \bullet \mathrm{cm} \bullet \mathrm{s}$ had a normal Eckardt score (median 3) in the setting of $>80 \%$ complete bolus transit, whereas those with a $\mathrm{DCl}$ $<100 \mathrm{mmHg} \bullet \mathrm{cm} \bullet \mathrm{s}$ had a median Eckardt score of 9. Our study is the first to correlate patient reported outcomes with HRM metrics in IEM. We feel this difference provides enough evidence for conservative management of IEM with $\mathrm{DCl}>100 \mathrm{mmHg} \bullet \mathrm{cm} \bullet \mathrm{s}$. Conversely, it may be reasonable to trial procholinergic agents such as bethanechol in patients with a median $\mathrm{DCl}<100 \mathrm{mmHg} \bullet \mathrm{cm} \bullet \mathrm{s}$ and dysphagia. The clinical implication of our reflux analysis results is less certain. However, despite our low number of patients studied off PPI, the elevated AET in all of our patients with a median $\mathrm{DCl}<100 \mathrm{mmHg} \bullet \mathrm{cm} \bullet \mathrm{s}$ is important. This justifies more aggressive lifestyle or medical reflux treatment, or consideration of antireflux surgery such as a partial fundoplication, in this group. Our results do not clarify the mechanism or reflux or the cause-effect relationship between IEM and GERD-our findings do not imply IEM as a cause of GERD; the reverse could be equally true.

Our study has some limitations. A major limitation of our study is the fact that we included very few ${ }^{16}$ patients in our reflux analysis that were off PPI. A large portion of patients was only referred for manometry without $\mathrm{pH}$ testing. In order to assess a reflux outcome, we included patients' on-PPI threshold using a threshold of $1.6 \%$ for abnormal AET based on prior literature. ${ }^{25,26}$ Secondly, we did not include a control population for comparison of bolus transit. Although the analysis has not been repeated using the EPT definition; bolus transit in IEM has been compared extensively to normal manometry and more subtle peristaltic abnormalities using CLT and impedance line tracings and was thus not an aim of our study. ${ }^{4-6}$ Thirdly, our HRIM protocol does not include viscous swallows, which might improve the sensitivity for detecting abnormal bolus transit. ${ }^{27}$ Fourthly, we included patients with prior fundoplication given the relevance of IEM in this population, although clearance could arguably be impaired. However, we found that impaired lower esophageal sphincter relaxation, possibly related to a fundoplication wrap, was not associated with poor bolus clearance. Additionally, 5 of our 10 fundoplication patients had incomplete clearance, which is in keeping with the rest of our cohort. Finally, we currently do not have long-term clinical outcome data to address whether IEM patients with $\mathrm{DCl}<100 \mathrm{mmHg} \bullet \mathrm{cm} \bullet$ s results in a more unfavorable clinical aftermath. 
There have been multiple proposed methods of characterizing bolus clearance on impedance manometry, including in IEM. Carlson et $\mathrm{al}^{28}$ found that the bolus flow time (BFT) and esophageal impedance integral (EII) correlated with non-obstructive dysphagia. Omari et al. ${ }^{29}$ found that time from nadir impedance to peak pressure (TNadImp) and impedance radio (IR) are other useful pressureflow-analysis (PFA) metrics for analyzing bolus clearance. Our goal was to study a universally available method that could be utilized by clinical gastroenterologists. Our group recently showed that the conventional line tracing method of evaluating bolus transit and colored contour method were useful in measuring bolus transit in achalasia and esophagogastric junction outflow obstruction (EGJOO). ${ }^{30}$ We have now shown similar reliability between these two methods in IEM. There may be future utility in performing PFA for a more nuanced characterization of bolus transit abnormalities in IEM.

In summary, our study shows that $50 \%$ or more failed peristalsis in IEM is associated with poor bolus clearance and a higher degree of dysphagia. This group of severe IEM also likely has elevated acid exposure. Further outcome analysis and therapeutic trials are needed to address the longer term clinical significance of phenotyping IEM and for development of an IEM management guideline.

\section{DISCLOSURES}

None.

\section{AUTHOR CONTRIBUTIONS}

AJ planned the study, collected, analyzed and interpreted the data, and drafted the manuscript. JB collected and interpreted the data, and edited the manuscript. JC planned the study, interpreted the data, edited and approved the final manuscript. All authors have approved the submitted final draft.

\section{ORCID}

A. Jain (iD http://orcid.org/0000-0002-2632-8624

\section{REFERENCES}

1. Kahrilas PJ, Dodds WJ, Hogan WJ, Kern M, Arndorfer RC, Reece A. Esophageal peristaltic dysfunction in peptic esophagitis. Gastroenterology. 1986;91:897-904.

2. Leite LP, Johnston BT, Barrett J, Castell JA, Castell DO. Ineffective esophageal motility (IEM): the primary finding in patients with nonspecific esophageal motility disorder. Dig Dis Sci. 1997;42:1859-1865.

3. Tutuian R, Vela MF, Balaji NS, et al. Esophageal function testing with combined multichannel intraluminal impedance and manometry: multicenter study in healthy volunteers. Clin Gastroenterol Hepatol. 2003;1:174-182.

4. Tutuian R, Castell DO. Clarification of the esophageal function defect in patients with manometric ineffective esophageal motility: studies using combined impedance-manometry. Clin Gastroenterol Hepatol. 2004;2:230-236.
5. Tutuian R, Castell DO. Combined multichannel intraluminal impedance and manometry clarifies esophageal function abnormalities: study in 350 patients. Am J Gastroenterol. 2004;99:1011-1019.

6. Blonski W, Vela M, Safder A, Hila A, Castell DO. Revised criterion for diagnosis of ineffective esophageal motility is associated with more frequent dysphagia and greater bolus transit abnormalities. Am J Gastroenterol. 2008;103:699-704.

7. Kim KY, Kim GH, Kim DU, et al. Is ineffective esophageal motility associated with gastropharyngeal reflux disease? World J Gastroenterol. 2008;14:6030-6035.

8. Vinjirayer E, Gonzalez B, Brensinger C, et al. Ineffective motility is not a marker for gastroesophageal reflux disease. Am J Gastroenterol. 2003;98:771-776.

9. Xiao Y, Kahrilas PJ, Kwasny MJ, et al. High-resolution manometry correlates of ineffective esophageal motility. Am J Gastroenterol. 2012;107:1647-1654.

10. Abdel Jalil AA, Castell DO. Ineffective esophageal motility (IEM): the old-new frontier in esophagology. Curr Gastroenterol Rep. 2016; 18:1.

11. Ravi K, Friesen L, Issaka R, Kahrilas PJ, Pandolfino JE. Long-term outcomes of patients with normal or minor motor function abnormalities detected by high-resolution esophageal manometry. Clin Gastroenterol Hepatol. 2015;13:1416-1423.

12. Chen $\mathrm{JH}$. Ineffective esophageal motility and the vagus: current challenges and future prospects. Clin Exp Gastroenterol. 2016;9: 291-299.

13. Agrawal A, Hila A, Tutuian R, Mainie I, Castell DO. Bethanechol improves smooth muscle function in patients with severe ineffective esophageal motility. J Clin Gastroenterol. 2007;41:366-370.

14. Broeders JA, Sportel IG, Jamieson GG, et al. Impact of ineffective oesophageal motility and wrap type on dysphagia after laparoscopic fundoplication. Br J Surg. 2011;98:1414-1421.

15. Kahrilas PJ, Bredenoord AJ, Fox M, et al. The Chicago Classification of esophageal motility disorders, v3.0. Neurogastroenterol Motil. 2015;27:160-174.

16. Min YW, Shin I, Son HJ, Rhee PL. Multiple rapid swallow maneuver enhances the clinical utility of high-resolution manometry in patients showing ineffective esophageal motility. Medicine (Baltimore). 2015;94:e1669.

17. Hiestand M, Abdel Jalil A, Castell DO. Manometric subtypes of ineffective esophageal motility. Clin Transl Gastroenterol. 2017;8:e78.

18. Mello MD, Shriver AR, Li Y, Patel A, Gyawali CP. Ineffective esophageal motility phenotypes following fundoplication in gastroesophageal reflux disease. Neurogastroenterol Motil. 2016;28:292-298.

19. Shaker A, Stoikes N, Drapekin J, Kushnir V, Brunt LM, Gyawali CP. Multiple rapid swallow responses during esophageal high-resolution manometry reflect esophageal body peristaltic reserve. Am J Gastroenterol. 2013;108:1706-1712.

20. Junginger T, Kneist W, Sultanov F, Eckardt VF. [Long-term outcome of myotomy and semi-fundoplication in achalasia]. Chirurg. 2002;73:704-709.

21. Jonasson C, Wernersson B, Hoff DA, Hatlebakk JG. Validation of the GerdQ questionnaire for the diagnosis of gastro-oesophageal reflux disease. Aliment Pharmacol Ther. 2013;37:564-572.

22. Roman S, Pandolfino JE, Chen J, Boris L, Luger D, Kahrilas PJ. Phenotypes and clinical context of hypercontractility in high-resolution esophageal pressure topography (EPT). Am J Gastroenterol. 2012; 107:37-45

23. Park MI. Recent concept in interpreting high-resolution manometry. $J$ Neurogastroenterol Motil. 2010;16:90-93.

24. Sifrim D, Castell D, Dent J, Kahrilas PJ. Gastro-oesophageal reflux monitoring: review and consensus report on detection and definitions of acid, non-acid, and gas reflux. Gut. 2004;53:1024-1031.

25. Katzka DA, Paoletti V, Leite L, Castell DO. Prolonged ambulatory $\mathrm{pH}$ monitoring in patients with persistent gastroesophageal 
reflux disease symptoms: testing while on therapy identifies the need for more aggressive anti-reflux therapy. Am J Gastroenterol. 1996;91:2110-2113.

26. Srinivasan R, Katz PO, Ramakrishnan A, Katzka DA, Vela MF, Castell DO. Maximal acid reflux control for Barrett's oesophagus: feasible and effective. Aliment Pharmacol Ther. 2001;15:519-524.

27. Koya DL, Agrawal A, Freeman JE, Castell DO. Impedance detected abnormal bolus transit in patients with normal esophageal manometry. Sensitive indicator of esophageal functional abnormality? Dis Esophagus. 2008;21:563-569.

28. Carlson DA, Omari T, Lin Z, et al. High-resolution impedance manometry parameters enhance the esophageal motility evaluation in nonobstructive dysphagia patients without a major Chicago Classification motility disorder. Neurogastroenterol Motil 2017; 29. https://doi. org/10.1111/nmo.12941
29. Omari TI, Szczesniak MM, Maclean J, et al. Correlation of esophageal pressure-flow analysis findings with bolus transit patterns on videofluoroscopy. Dis Esophagus. 2016;29:166-173.

30. Jain A, Baker JR, Rubenstein JH, Chen JW. Bolus clearance in esophagogastric junction outflow obstruction is associated with strength of peristalsis. Neurogastroenterol Motil 2017. https://doi.org/10.1111/ nmo.13093

How to cite this article: Jain A, Baker JR, Chen JW. In ineffective esophageal motility, failed swallows are more functionally relevant than weak swallows. Neurogastroenterol Motil. 2018;30:e13297. https://doi.org/10.1111/nmo.13297 